\title{
The Regulatory Effects of Long Noncoding RNA-ANCR on Dental Tissue-Derived Stem Cells
}

\author{
Qian Jia, ${ }^{1}$ Xiaolin Chen, ${ }^{2,3}$ Wenkai Jiang, ${ }^{3}$ Wei Wang, ${ }^{3}$ Bin Guo, ${ }^{1}$ and Longxing $\mathrm{Ni}^{3}$ \\ ${ }^{1}$ Institution of Stomatology, The PLA General Hospital, No. 28 Fuxing Road, Beijing 100853, China \\ ${ }^{2}$ Department of Endodontics, Xiamen Stomatology Hospital, Teaching Hospital of Fujian Medical University, No. 1309 Lvling Road, \\ Xiamen, Fujian 361003, China \\ ${ }^{3}$ State Key Laboratory of Military Stomatology \& National Clinical Research Center for Oral Diseases \& Shaanxi Key Laboratory of \\ Oral Diseases, Department of Operative Dentistry \& Endodontics, School of Stomatology, Fourth Military Medical University, \\ No. 145 Western Changle Road, Xian, Shaanxi 710032, China
}

Correspondence should be addressed to Bin Guo; guobin0408@126.com and Longxing Ni; longxing_ni@hotmail.com

Received 17 May 2016; Revised 6 July 2016; Accepted 10 July 2016

Academic Editor: Hung-Fat Tse

Copyright (C) 2016 Qian Jia et al. This is an open access article distributed under the Creative Commons Attribution License, which permits unrestricted use, distribution, and reproduction in any medium, provided the original work is properly cited.

Long noncoding RNAs (lncRNA) have been recognized as important regulators in diverse biological processes, such as transcriptional regulation, stem cell proliferation, and differentiation. Previous study has demonstrated that lncRNA-ANCR (antidifferentiation ncRNA) plays a key role in regulating the proliferation and osteogenic differentiation of periodontal ligament stem cells (PDLSCs). However, little is known about the role of ANCR in regulating other types of dental tissue-derived stem cells (DTSCs) behaviours (including proliferation and multiple-potential of differentiation). In this study, we investigated the regulatory effects of $\ln$ CRNA-ANCR on the proliferation and differentiation (including osteogenic, adipogenic, and neurogenic differentiation) of DTSCs, including dental pulp stem cells (DPSCs), PDLSCs, and stem cells from the apical papilla (SCAP) by downregulation of lncRNA-ANCR. We found that downregulation of ANCR exerted little effect on proliferation of DPSCs and SCAP but promoted the osteogenic, adipogenic, and neurogenic differentiation of DTSCs. These data provide an insight into the regulatory effects of long noncoding RNA-ANCR on DTSCs and indicate that ANCR is a very important regulatory factor in stem cell differentiation.

\section{Introduction}

Dental tissue-derived stem cells (DTSCs) are stem cells separated from the dental tissue that have self-proliferation and multidirectional differentiation potential. Dental pulp stem cells (DPSCs), periodontal ligament stem cells (PDLSCs), and stem cells from the apical papilla (SCAP) are three important DTSCs which are used in tissue engineering research [1-4]. Hilkens et al. found that DPSCs are capable of osteogenic, adipogenic, and chondrogenic differentiation via different induction methods [5]. Kim et al. induced differentiation of DPSCs into cementoblast and neurocyteslike cells [6]. Dissanayaka and Janebodin found that DPSCs could be differentiated into vascular endothelial cells and had angiopoietic abilities after stimulation with an angiopoietic factor $[7,8]$. Seo et al. combined PDLSCs with HA/TCP and implanted the complex into a nude mouse where the
PDLSCs formed periodontium and cementum-like tissues [2]. Sonoyama et al. seeded PDLSCs and SCAP mixed cells into HA/TCP and implanted the complex into young swine where the mixed cells formed functional bioroot and periodontium [9].

Many factors, including growth factors, inflammatory factors, and microRNAs, play important roles in regulating the proliferation and differentiation of DTSCs (Table 1) [7, 1025]. After lucubration on the regulatory effects of microRNAs on DTSCs, scholars discovered that many noncoding RNAs were key regulating factors in the proliferation and differentiation of DTSCs [14-16].

While $93 \%$ of human genomic DNA is translated into RNA, only $2 \%$ of RNA is transcribed into protein. Most of the DNA is translated into noncoding RNAs [26]. Long noncoding RNA (lncRNA) used to be recognized as useless transcriptional noise [27]. In recent years, scientists discovered 
TABLE 1: The effects of different regulating factors on DTSC.

\begin{tabular}{lccc}
\hline Research team & Cell & Regulating factors & Regulatory effect \\
\hline Osathanon et al. [10] & DPSC & BFGF & Inhibit osteogenic differentiation \\
Dissanayaka et al. [7] & DPSC & VEGF & Promote angiopoietic differentiation \\
Feng et al. [11] & DPSC & IGF & Promote osteogenic differentiation \\
He et al. [12] & DPSC & IL-1, TNF- $\alpha$ & Promote osteogenic differentiation \\
Yang et al. [13] & DPSC & MicroRNA-218 & Promote osteogenic differentiation \\
Gay et al. [14] & DPSC & MicroRNA-720 & Inhibit osteogenic differentiation \\
Hara et al. [15] & DPSC & MicroRNA-21 & Promote osteogenic differentiation \\
Wei et al. [16] & PDLSC & BMP9 & Promote osteogenic differentiation \\
Ye et al. [17] & PDLSC & BFGF & Promote osteogenic differentiation \\
Osathanon et al. [18] & PDLSC & NF -B & Inhibit osteogenic differentiation \\
Chen et al. [19] & BDP2 & Promote osteogenic differentiation \\
Song et al. [20] & PDLSC & Notch signaling & Promote adipogenic differentiation \\
Osathanon et al. [21] & PDLSC & BFGF & Promote neurogenic differentiation \\
Wu et al. [22] & SCAP & Canonical Wnt pathway & Inhibit osteogenic differentiation \\
Wang et al. [23] & SCAP & BMP2 & Promote osteogenic differentiation \\
Zhang et al. [24] & SCAP & 17 $\beta$ estradiol & Promote osteogenic differentiation \\
Li et al. [25] & SCAP & & Promote osteogenic differentiation \\
\hline
\end{tabular}

that they were very important in regulating epigenetic, transcriptional, and posttranscriptional gene expression [26-31]. Antidifferentiation noncoding RNA $(A N C R)$ is a newly found lncRNA that is downregulated during stem cell differentiation and required to keep epidermal stem cells or osteoblast cells in an undifferentiated cell state. Depleting ANCR in progenitor-containing populations, without any other stimuli, resulted in rapid differentiation and gene induction [32]. $\mathrm{Zhu}$ and $\mathrm{Xu}$ found that downregulating ANCR promoted osteoblast differentiation by targeting EZH2 and regulating Runx2 expression [33]. Additionally, our previous research also showed that ANCR promoted the osteogenic differentiation of PDLSCs [34]. In this experiment, we used RNA interference to downregulate $A N C R$ expression to further analyze the regulatory function of $A N C R$ on the proliferation and differentiation of DTSCs, which would give a laterally comparative view on the regulatory function of ANCR on DTSCs.

\section{Materials and Methods}

2.1. Sample Collection and Cell Culture. Healthy impacted third molars were collected from adult humans between 19 and 29 years old from the dental hospital of the Fourth Military Medical University. All tooth extractions were conducted under the approval of the Ethical Committee of School of Stomatology, Fourth Military Medical University (permission number IRB-REV-2014-018). Informed consent was obtained from all subjects and the methods were carried out in accordance with the approved guidelines. Tissues from the dental pulp, periodontal ligament, and apical papilla were isolated from each molar, as previously described [1$3,35]$. Briefly, the tissues were gently separated and digested in a solution composed of $3 \mathrm{mg} / \mathrm{mL}$ of collagenase type I (Invitrogen, USA) and $4 \mathrm{mg} / \mathrm{mL}$ of dispase (Invitrogen, USA) for $40 \mathrm{~min}$ at $37^{\circ} \mathrm{C}$. The cell suspension was obtained by passing the solution through a $70-\mu \mathrm{m}$ strainer. Then, $1 \times$ $10^{4}$ cells were seeded into each well of a 6 -well plate. $\alpha$ modification of Eagle's Medium ( $\alpha$-MEM, Invitrogen, USA) supplemented with $10 \%$ fetal bovine serum (HyClone, USA), $100 \mathrm{~mol} / \mathrm{L}$ of L-ascorbic acid 2-phosphate (Sigma, USA), $2 \mathrm{mmol} / \mathrm{L}$ of L-glutamine (Sigma, USA), $100 \mathrm{U} / \mathrm{mL}$ of penicillin, and $100 \mu \mathrm{g} / \mathrm{mL}$ of streptomycin (Gibco, USA) was used as the standard culturing medium for cells at $37^{\circ} \mathrm{C}$ with $5 \%$ $\mathrm{CO}_{2}$. The medium was changed every 2-3 days. A limited dilution technique was applied and single cells were seeded into a 96-well plate to obtain single cell-derived colonies. Upon reaching $80 \%$ confluency, a number of these singlecolony-derived lines were passaged at a $1: 3$ ratio for further culturing.

2.2. Immunophenotype Analysis. DTSCs were stained with stem cell surface markers and analyzed by flow cytometry as described previously [16]. Briefly, to identify the phenotypes of DTSCs, $5 \times 10^{5}$ cells at the 3 rd passage were incubated with phycoerythrin (PE) conjugated monoclonal antibodies for human CD29, CD34, CD45, CD90, and CD146 or Allophycocyanin (APC) conjugated monoclonal antibody against human STRO-1, based on the manufacturer's instructions. The incubation procedure was carried out at $4^{\circ} \mathrm{C}$ away from light for $1 \mathrm{~h}$. After washing with PBS, the cells were subjected to flow cytometric analysis.

2.3. Lentivirus Infection. The third-passage self-inactivating lentivirus vector was purchased from Neuron Biotech (Shanghai Neuron Biotech Co., Ltd., Shanghai, China). The vector contained a puromycin marker and U6 PolIII promoter, which allowed the introduction of oligonucleotides encoding short hairpin RNAs (shRNAs) and synthetic oligonucleotides containing the human ANCR (NCBI accession number 
NR_024031.1) splice variant target sequence (GCTGACCCTTACCCTGAATAC). The sequences for cloning were synthesized, annealed, and ligated into the pLKD-CMV-G lentiviral vector between the AgeI and EcoRI enzyme sites after the U6 promoter. The oligonucleotide sequences were $5^{\prime}$-CCGGGCTGACCCTTACCCTGAATACCTCGAGGTATTCAGGGTAAGGGTCAGCTTTTTT-3' (sense); and $5^{\prime}$-AATTCAAAAAAGCTGACCCTTACCCTGAATACCTCGAGGTATTCAGGGTAAGGGTCAGC- ${ }^{\prime}$ (antisense). DTSCs at passage 3 were plated at a density of $5 \times 10^{4}$ cells/well into 6-well plates. The cells were cultured for 3 days along with recombinant lentivirus encoding shRNA against ANCR at a multiplicity of infection (MOI) of 10, in $\alpha$-MEM supplemented with $10 \%$ FBS containing $5 \mathrm{mg} / \mathrm{mL}$ of polybrene at $37^{\circ} \mathrm{C}$ and $5 \% \mathrm{CO}_{2}$. The cells were then replated in $25-\mathrm{cm}^{2}$ flasks in $90 \% \alpha$-MEM, $10 \%$ FBS, and $5 \mu \mathrm{g} / \mathrm{mL}$ of puromycin and cultured at $37^{\circ} \mathrm{C}$ with $5 \% \mathrm{CO}_{2}$ and constant humidity. The ANCR expression after ANCR-RNA interference (RNAi) was examined by qRT-PCR analysis. Cells successfully infected with specific ANCR-RNAi were designated as DPSC/ANCR-RNAi, PDLSC/ANCR-RNAi, and SCAP/ANCR-RNAi, while the wild-type DTSCs were designated as DPSC/wt, PDLSC/wt, and SCAP/wt and cells infected by control lentivirus vector were designated as DPSC/vector, PDLSC/vector, and SCAP/vector.

2.4. Cell Viability Assay (CCK8 Kit). Cells were seeded into two 96-well plates at a density of approximately $1 \times 10^{4}$ cells per well. The assay was performed $24 \mathrm{~h}$ after seeding and lasted for 7 days; data were collected at the same time point each day. A Cell Counting Kit-8 (CCK8) was used to perform this experiment. The number of cells per well was tested by the absorbance $(450 \mathrm{~nm})$ of reduced WST- 8 at the indicated time points.

2.5. Cell Viability Assay (Edu Kit). Cells were seeded into two 96-well plates at a density of approximately $1 \times 10^{4}$ cells per well and cultivated to logarithmic phase. Then, the cell viability assay was performed with Edu kit (RiboBio, China) as the manufacturers' instruction. Briefly, $50 \mu \mathrm{M}$ 5-ethynyl$2^{\prime}$-deoxyuridine $(\mathrm{Edu})$ was added into the culture medium and cells were cultured for 2 hours. After 2-time PBS washing and paraformaldehyde fixation, the cell nucleus were stained with Apollo 567 and Hoechst 33342. Then, the cells were imaged with a laser scanning confocal microscope (Zeiss, Germany) at $550 \mathrm{~nm}$ and $350 \mathrm{~nm}$ in the same vision. Then, the images of the same vision were overlapped in one image. Cell counting was done by Image J.

2.6. Alkaline Phosphatase (ALP) Activity Quantification. Cells were seeded into 96-well plates at approximately $1 \times 10^{5}$ cells per well. $24 \mathrm{~h}$ after seeding, the medium was changed into standard osteogenic differentiation induction medium $(50 \mathrm{mg} / \mathrm{mL}$ of ascorbic acid (Sigma, USA)), $10 \mathrm{mmol} / \mathrm{L}$ of beta-glycerophosphate (BGP, Sigma, USA) and $10 \mathrm{ng} / \mathrm{mL}$ of dexamethasone diluted in 10\% FBS $\alpha$-MEM. ALP quantification assay was performed at $3,6,9,12,15,18$, and 21 days using an alkaline phosphatase assay quantification kit (JianCheng,
China). The results were measured spectrophotometrically at a wavelength of $520 \mathrm{~nm}$, based upon the manufacturer's instructions.

2.7. Alizarin Red Staining and Quantification. Cells were seeded into 24 -well plates at a density of approximately $1 \times 10^{5}$ cells per well separately. After cells reached $80 \%$ confluence, the medium was changed into standard osteogenic differentiation induction medium and then cultured for another 3 weeks. The induction medium was changed every 3 days. Finally, cells were stained with Alizarin red $(\mathrm{pH}=4.1)$ staining solution and were quantified according to previously described methods [10].

2.8. Oil Red O Staining. Cells were seeded into 24-well plates at a density of approximately $1 \times 10^{5}$ cells per well. After the cells reached $80 \%$ confluence, the medium was changed into standard adipogenic differentiation induction medium $(0.5 \mathrm{mmol} / \mathrm{L}$ of methylisobutylxanthine (Sigma, USA), $1 \mathrm{mmol} / \mathrm{L}$ of dexamethasone, $10 \mu \mathrm{g} / \mathrm{mL}$ of insulin (Sigma, USA), and $200 \mu \mathrm{mol} / \mathrm{L}$ of indomethacin (Sigma, USA)) and then cultured for another 3 weeks. The induction medium was changed every 3 days. Finally, cells were stained with Oil red O staining solution and microscopically observed under phase contrast (Zeiss, Germany).

2.9. Immunofluorescence. Cells were seeded into confocal dishes at approximately $1 \times 10^{5}$ cells per well. After adherence, the culturing medium was changed into neurogenic differentiation induction medium (Gibco, USA) containing $20 \mathrm{ng} / \mathrm{mL}$ of EGF (Calbiochem, USA) and $20 \mathrm{ng} / \mathrm{mL}$ of bFGF (Calbiochem, USA) and then cultured for another 2 weeks. The induction medium was changed every 3 days. Finally, cells were stained with mouse anti-human BIII-TUBULIN primary antibody (Cell Signaling Technology, USA) at a concentration of 1:100. After overnight incubation, the cells were stained with DyLight 405 (ThermoFisher, USA) at a concentration of 1:50 and Hoechst dye (RiboBio, China) at a concentration of $1: 100$. Then, the cells were imaged with a laser scanning confocal microscope (Zeiss, Germany).

2.10. Quantitative Real-Time Polymerase Chain Reaction (Q$P C R)$. Cells were seeded into $60-\mathrm{mm}$ dishes. At $80 \%$ confluence, cells were induced by osteogenic/adipogenic/neurogenic differentiation medium for 2 weeks. Then, the total RNA was extracted from cells using Trizol reagent (TAKARA, Japan), and a reverse-transcription reaction was performed using a TAKARA reverse transcriptase kit (TAKARA, Japan). Real-time PCR was performed using a standard SYBR Green PCR kit (TAKARA, Japan) protocol on an Applied Biosystems 7500 real-time PCR system (Applied Biosystems, USA), according to the manufacturer's instructions. $\beta$-ACTIN was used as an internal reference. The mRNA expression of osteogenic, adipogenic, and neurogenic marker genes was analyzed. Each sample was analyzed in triplicate. The $2^{-\Delta \Delta \mathrm{Ct}}$ value was used to determine the relative expression levels. The 
TABle 2: Primer sequences.

\begin{tabular}{|c|c|c|}
\hline & Primer & Sequence $\left(5^{\prime}-3^{\prime}\right)$ \\
\hline & $\beta$-ACTIN-forward & TGGCACCCAGCACAATGAA \\
\hline & $\beta$-ACTIN-reverse & CTAAGTCATAGTCCGCCTAGAAGCA \\
\hline & ANCR-forward & GCCACTATGTAGCGGGTTTC \\
\hline & ANCR-reverse & ACCTGCGCTAAGAACTGAGG \\
\hline \multirow{6}{*}{ Osteogenic differentiation marker genes } & $A L P$-forward & CCACGTCTTCACATTTGGTG \\
\hline & $A L P$-reverse & AGACTGCGCCTGGTAGTTGT \\
\hline & $O C N$-forward & GGCAGCGAGGTAGTGAAGAG \\
\hline & OCN-reverse & CTGGAGAGGAGCAGAACTGG \\
\hline & $B S P$-forward & AAAGTGAGAACGGGGAACCT \\
\hline & $B S P$-reverse & GATGCAAAGCCAGAATGGAT \\
\hline \multirow{4}{*}{ Adipogenic differentiation marker genes } & $P P A R-\gamma 2$-forward & CATTCTGGCCCACCAACTT \\
\hline & $P P A R-\gamma 2$-reverse & CCTTGCATCCTTCACAAGCA \\
\hline & $C / E B P \alpha$-forward & TGGACAAGAACAGCAACGAG \\
\hline & $C / E B P \alpha$-reverse & TTGTCACTGGTCAGCTCCAG \\
\hline \multirow{8}{*}{ Neurogenic differentiation marker genes } & $\beta I I I-T U B U L I N$-forward & GGCСTCTTCTCACAAGTACG \\
\hline & $\beta I I I-T U B U L I N$-reverse & CCACTCTGACCAAAGATGAAA \\
\hline & GAP43-forward & CCTGTGGGAGTCCACTTTCC \\
\hline & GAP43-reverse & CGATATTTTGGACTCCTCAGATGA \\
\hline & NEFL-forward & TGATGGTAATGGATTGGAACTATGA \\
\hline & NEFL-reverse & TCAACCCAGGTCTAGTAAGCAGAA \\
\hline & NESTIN-forward & GTAGCTCCCAGAGAGGGGAA \\
\hline & NESTIN-reverse & CTCTAGAGGGCCAGGGACTT \\
\hline
\end{tabular}

results were expressed as $\log _{10}\left(2^{-\Delta \Delta \mathrm{Ct}}\right)$. The gene names and primer sequences are shown in Table 2.

2.11. Statistical Analysis. Each experiment was performed at least three times, unless otherwise indicated. Data are reported as the mean $\pm \mathrm{SD}$ (Standard Deviation). The significance of the differences between the experimental and the control groups was determined by using post hoc analysis for ANOVA. A value of $P<0.05$ was considered to be statistically significant.

\section{Results}

3.1. The Characterization and ANCR Interference of DTSCs. Immunophenotype analysis showed that the separated DPSCs (Figure 1(a)), PDLSCs (Figure 1(b)), and SCAP (Figure 1(c)) were CD29, CD90, CD146, and STRO-1 positive and CD34 and CD45 negative. Q-PCR analysis was performed 3 days after infection. The results showed that ANCR was significantly knocked down by the ANCR-specific lentivirusdelivered shRNA in the ANCR-RNAi groups compared with control groups (wt and vector) in DPSCs (Figure 1(d)), PDLSCs (Figure 1(e)), and SCAP (Figure 1(f)).

3.2. The Effect of ANCR-RNAi on DTSC Proliferation. A cell viability assay using CCK8 kit was performed to quantify the proliferation of DTSCs. The results showed that the growth rate of cells from PDLSC/ANCR-RNAi group was increased compared with the control groups (Figure 2(b)). However, downregulating ANCR had little impact on DPSCs (Figure 2(a)) and SCAP (Figure 2(c)) proliferation. To confirm this result, we used Edu kit to analyze the cell viability. The results showed that there were more PDLSC/ANCR-RNAi cells (Figure 2(e)) in $S$ phase (purple) than control cells. However, there was little difference between ANCR-RNAi cells and control cells in DPSCs (Figure 2(d)) and SACP (Figure 2(f)). Cell counting by Image J confirmed this result (Figure 2(g)). In summary, downregulating ANCR promoted the cell viability of PDLSCs but had little effect on the cell viability of DPSCs and SCAP.

3.3. Downregulation of ANCR Promoted the Osteogenic Differentiation of DTSCs. ALP activity quantification showed that downregulating $A N C R$ increased $A L P$ secretion in DTSCs. A significant difference appeared at day 9 in DPSCs (Figure 3(a)) and SCAP (Figure 3(c)) but not until day 12 in PDLSCs (Figure 3(b)). The Alizarin red staining showed that ANCR-RNAi cells secreted more mineralizing matrix than the control groups. Quantification showed that the absorbance of DPSC/ANCR-RNAi cells (Figure 3(d)) was twofold higher than the control groups and the absorbance of PDLSC/ANCR-RNAi (Figure 3(e)) and SCAP/ANCR-RNAi (Figure 3(f)) cells was onefold higher than the control groups. $\mathrm{Q}-\mathrm{PCR}$ showed that all of the osteogenic marker genes $(A L P, B S P$, and $O C N)$ were upregulated in ANCR-RNAi cells (Figures 3(g)-3(I)). 

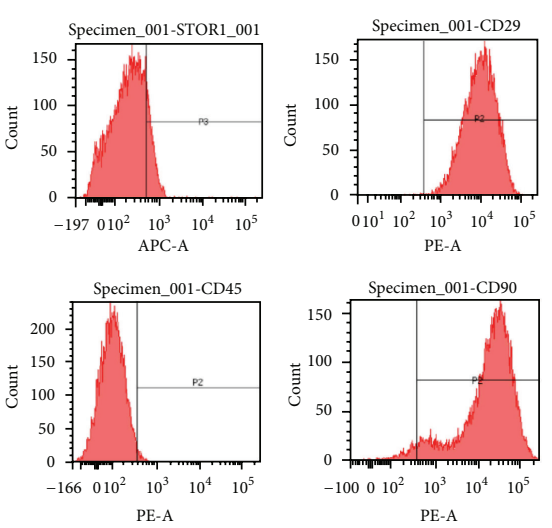

(a)
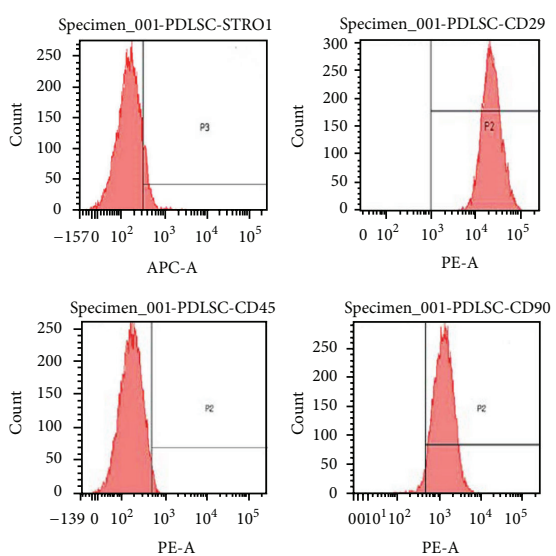

(b)
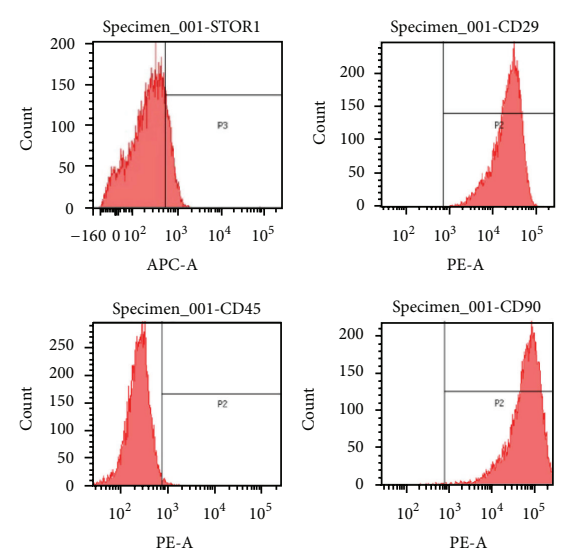

(c)
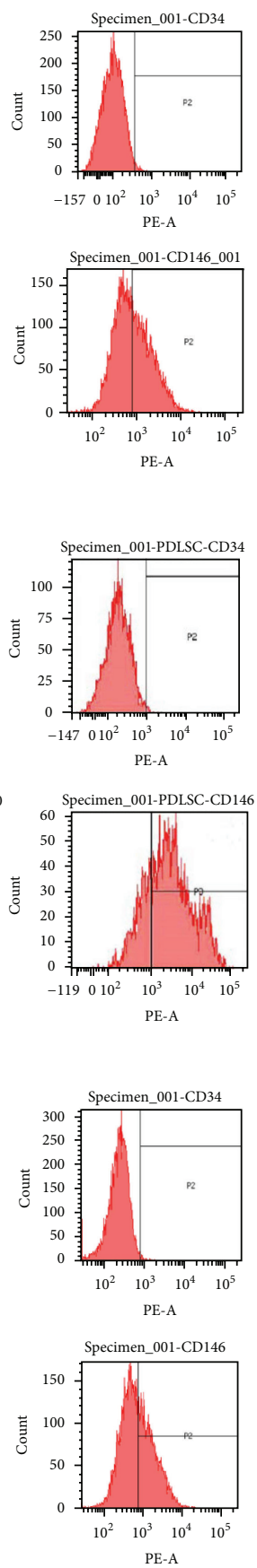
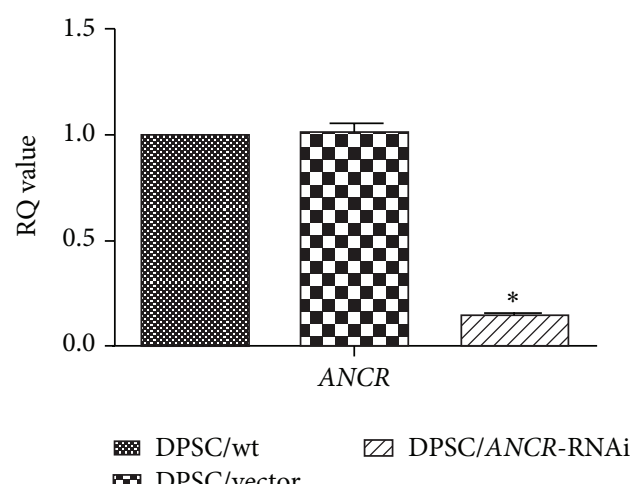

(d)

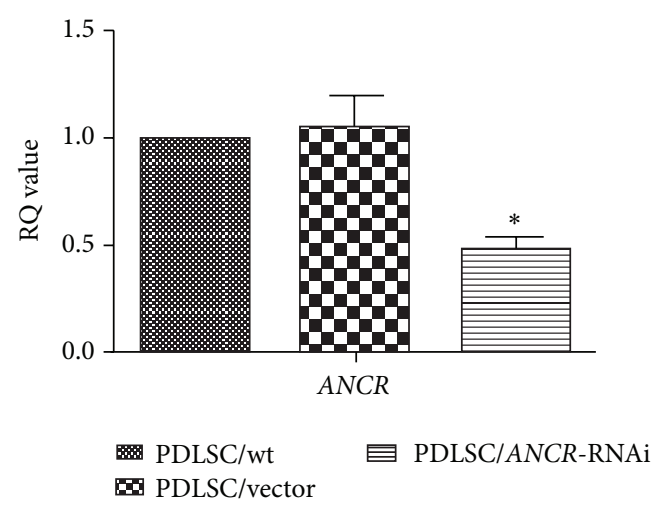

(e)

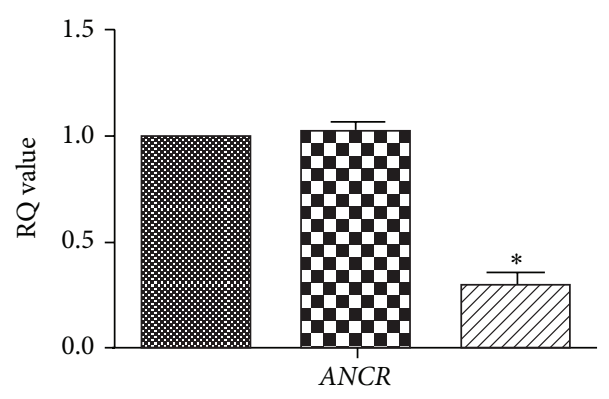

$\mathrm{R}$ SCAP/wt $\mathrm{SCAP} / A N C R-\mathrm{RNAi}$
$\mathrm{SCAP} / \mathrm{vector}$

(f)

Figure 1: The characterization and ANCR interference of DTSCs. The DPSCs (a), PDLSCs (b), and SCAP (c) that we isolated expressed mesenchymal stem cell markers, including CD29, CD90, CD146, and STRO-1, but were negative for the hematopoietic cell marker CD34 and leukocyte marker CD45. Three days after lentivirus infection, we evaluated the effects of ANCR-RNAi by Q-PCR. The results showed that ANCR expression in DPSC/ANCR-RNAi (d), PDLSC/ANCR-RNAi (e), and SCAP/ANCR-RNAi (f) cells was remarkably downregulated when compared with control cells. ${ }^{*} P<0.05$ when compared with the control group.

3.4. Downregulation of ANCR Promoted the Adipogenic Differentiation of DTSCs. Oil red O staining showed that downregulating ANCR promoted adipogenic differentiation of DPSCs (Figure 4(a)), PDLSCs (Figure 4(b)), and SCAP
(Figure 4(c)). Q-PCR showed that all of the adipogenic marker genes $(P P A R \gamma-2$ and $C / E B P \alpha)$ were upregulated in DPSCs (Figure 4(d)), PDLSCs (Figure 4(e)), and SCAP (Figure 4(f)). 


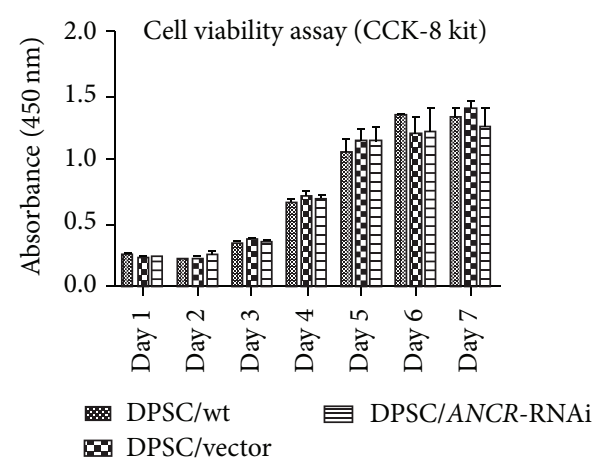

(a)

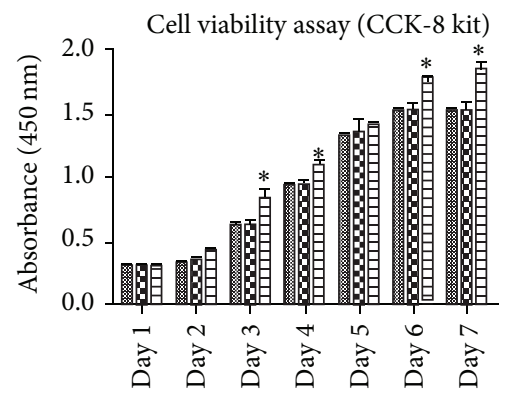

m PDLSC/wt $\square \mathrm{PDLSC/ANCR-RNAi}$ PDLSC/vector

(b)

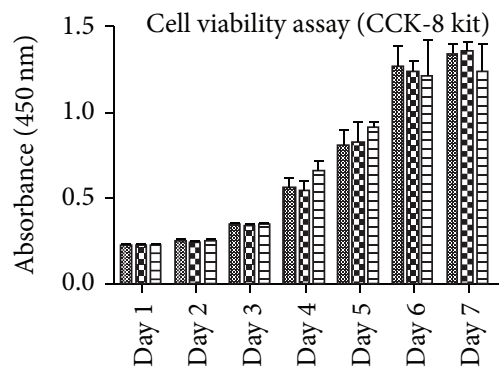

SCAP/wt $\mathrm{WSCAP/ANCR-RNAi}$

SCAP/vector

(c)

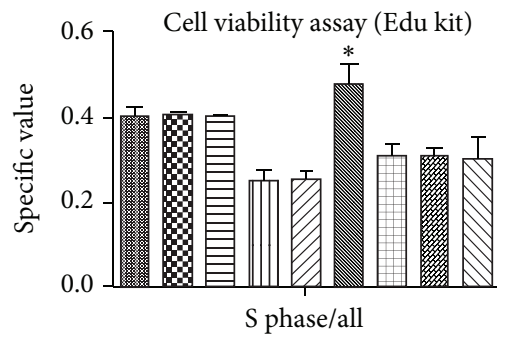

$$
\begin{array}{ll}
\square \text { DPSC-wt } & \square \text { PDLSC-ANCRi } \\
\text { DPSC-vector } & \square \text { SCAP-wt } \\
\boxminus \text { DPSC-ANCRi } & \square \text { SCAP-vector } \\
\text { m PDLSC-wt } & \square \text { SCAP-ANCRi } \\
\square \text { PDLSC-vector } &
\end{array}
$$

(g)

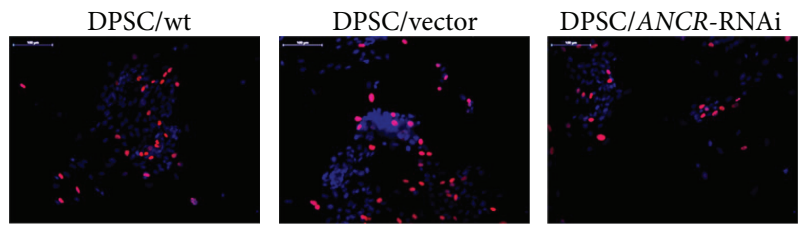

(d)

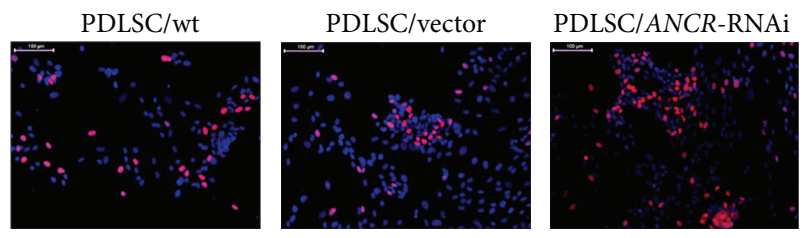

(e)
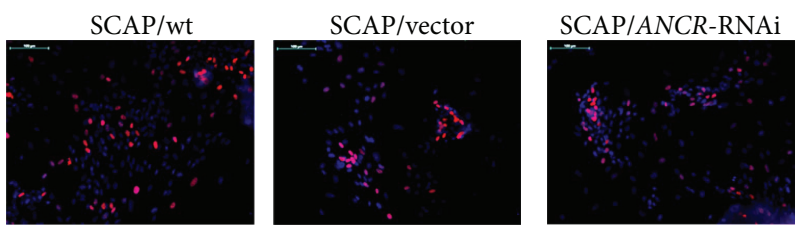

(f)

Figure 2: The effects of ANCR-RNAi on DTSCs proliferation. From day 1 to day 7, the cell viability of PDLSC/ANCR-RNAi cells (b) was greater than that of the control cells; however, there were no statistically significant differences in DPSCs (a) and SCAP (c). Edu assay showed that there were more PDLSC/ANCR-RNAi cells (e) in S phase (purple) than control cells. However, there was little difference between ANCRRNAi cells and control cells in DPSCs (d) and SACP (f). The cell counting result confirmed this result (g). The specific value of cells in S phase was higher in PDLSC/ANCR-RNAi cells compared to the control group; however, there were no statistically significant differences in DPSCs and SCAP. ${ }^{*} P<0.05$ when compared with the control group. Bars $100 \mu \mathrm{m}$. 


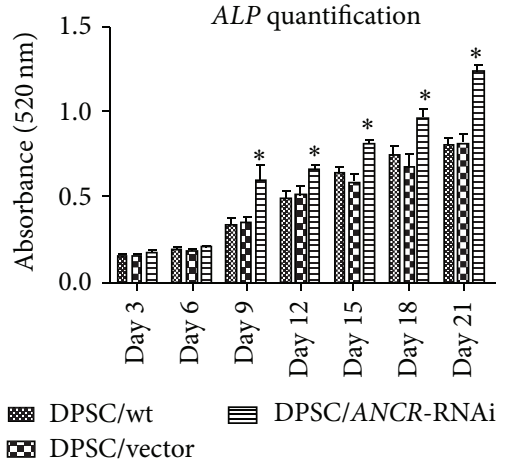

(a)

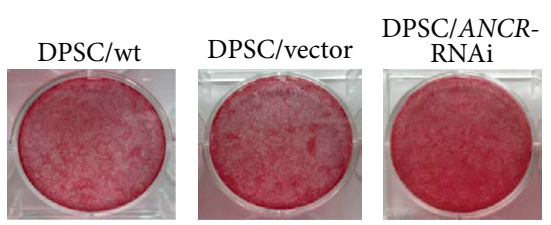

Alizarin red quantification
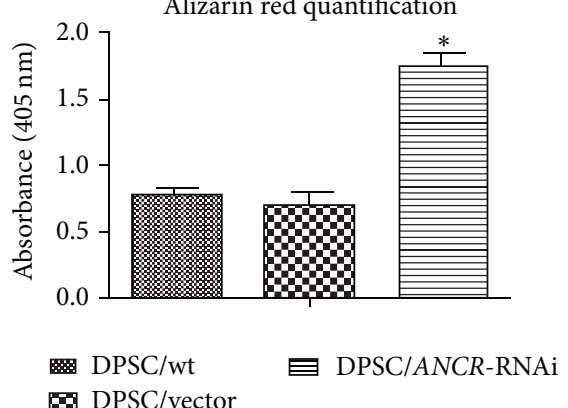

(d)

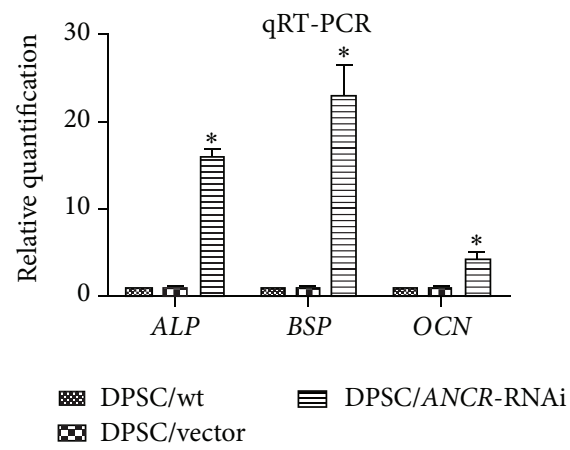

(g)

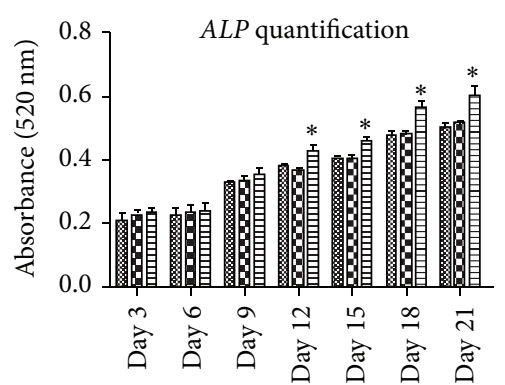

PDLSC/wt

(b)
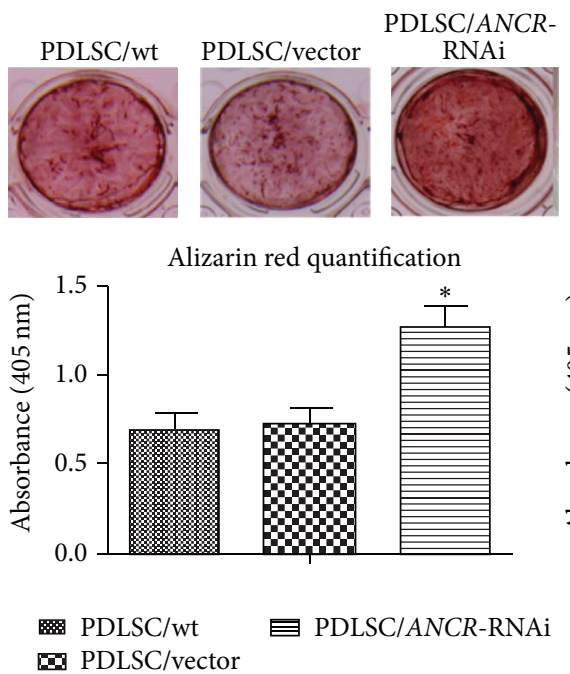

(e)

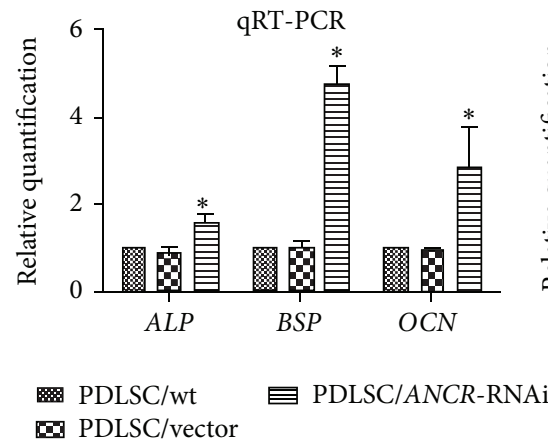

(h)

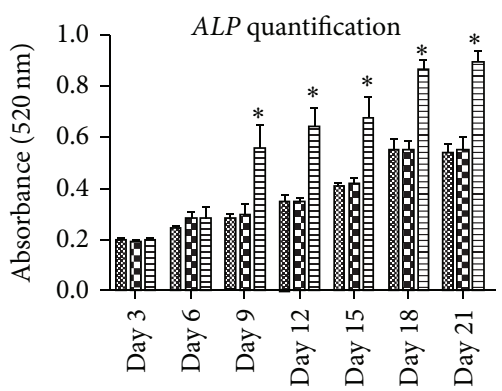

SCAP/wt 回 SCAP/ANCR-RNAi SCAP/vector

(c)

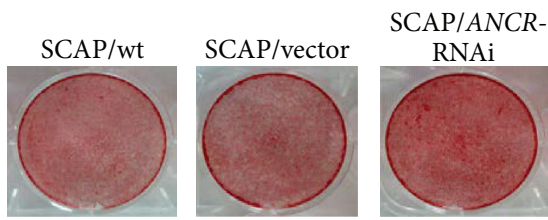

Alizarin red quantification

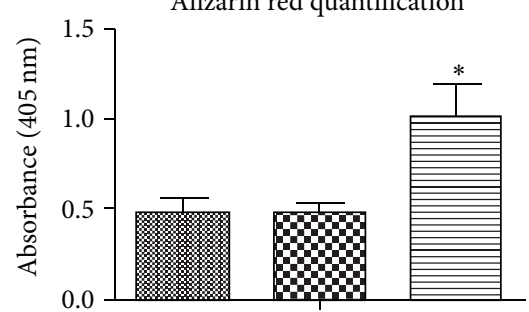

. $\mathrm{SCAP} / \mathrm{wt}$ Ð SCAP/ANCR-RNAi $\square \mathrm{SCAP} /$ vector

(f)

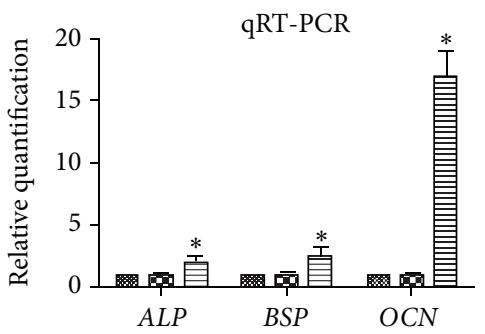

SCAP/wt $\square \mathrm{SCAP} / A N C R-\mathrm{RNAi}$ SCAP/vector

(i)

FIgURE 3: The effect of ANCR-RNAi on osteogenic differentiation in DTSCs. ALP activity was significantly increased in DPSC/ANCR-RNAi (a), PDLSC/ANCR-RNAi (b), and SCAP/ANCR-RNAi (c) cells when compared with control cells. Three weeks after induction, the cells were stained with Alizarin red ( $\mathrm{pH}=4.1)$, and DPSC/ANCR-RNAi (d), PDLSC/ANCR-RNAi (e), and SCAP/ANCR-RNAi (f) cells formed more mineralized nodules than the control groups. The Alizarin red quantification confirmed this result. The mRNA expression of $A L P, B S P$, and OCN was upregulated in DPSC/ANCR-RNAi (g), PDLSC/ANCR-RNAi (h), and SCAP/ANCR-RNAi (i) cells compared with control cells after two weeks of induction. ${ }^{*} P<0.05$ when compared with the control group.

3.5. Downregulation of ANCR Promoted the Neurogenic Differentiation of DTSCs. Immunofluorescence showed stronger BIII-TUBULIN expression in DPSC/ANCRRNAi (Figure 5(a)), PDLSC/ANCR-RNAi (Figure 5(b)), and SCAP/ANCR-RNAi (Figure 5(c)) cells than in the control cells. After two weeks of induction, the cellular morphology of DPSC/ANCR-RNAi and PDLSC/ANCRRNAi cells was markedly changed compared with control groups. DPSC/ANCR-RNAi cells were connected by an axon/dendron-like structure that extended from the cell 

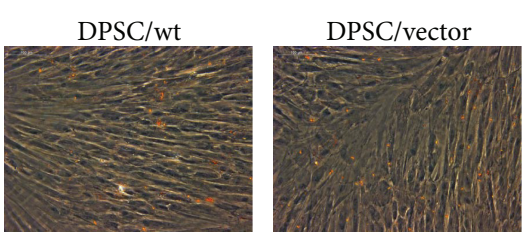

(a)
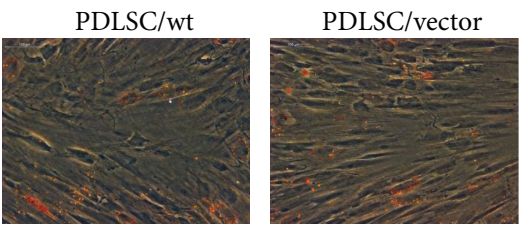

(b)
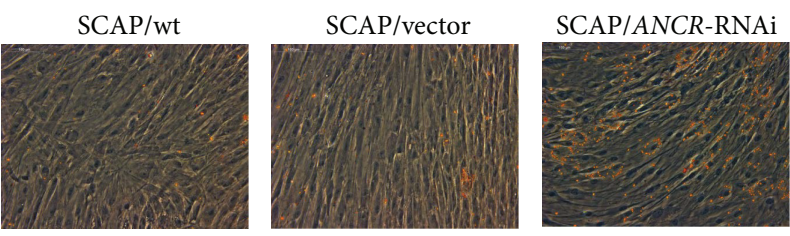

(c)

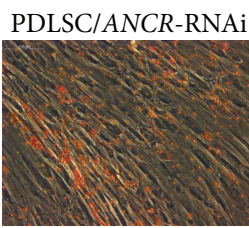

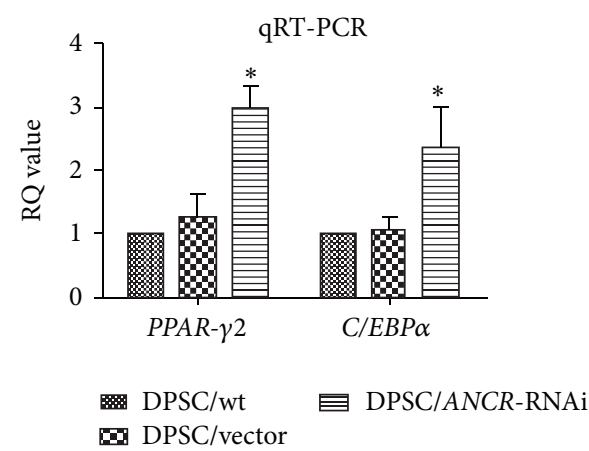

(d)

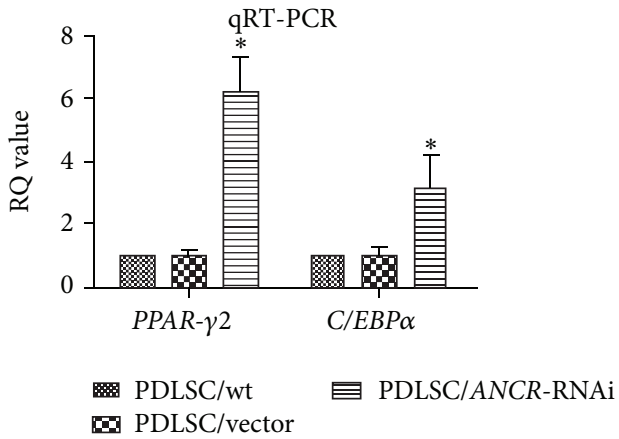

(e)

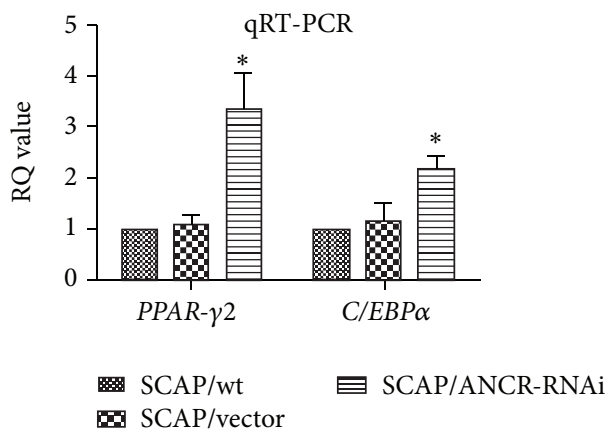

(f)

Figure 4: The effect of ANCR-RNAi on adipogenic differentiation in DTSCs. Oil red O staining showed that DPSC/ANCR-RNAi (a), PDLSC/ANCR-RNAi (b), and SCAP/ANCR-RNAi (c) cells formed more lipid droplets than the control groups. The mRNA expression of $P P A R-\gamma 2$ and C/EBP $\alpha$ was upregulated in DPSC/ANCR-RNAi (d), PDLSC/ANCR-RNAi (e), and SCAP/ANCR-RNAi (f) cells compared with control cells after 2 weeks of induction. ${ }^{*} P<0.05$ when compared with the control group.

body. The cellular morphology of the PDLSC/ANCR-RNAi cells became irregular triangles or oval. However, there was little change in the cellular morphology of SCAP/ANCRRNAi cells. Q-PCR showed that BIII-TUBULIN, GAP43, NEFL, and NESTIN were upregulated in DPSC/ANCR-RNAi cells (Figure 5(d)) compared with the control groups. In PDLSC/ANCR-RNAi cells (Figure 5(e)), BIII-TUBULIN and NESTIN were upregulated, while GAP43 and NEFL had little change compared with the control groups. In SCAP/ANCRRNAi cells (Figure 5(f)), BIII-TUBULIN, NEFL, and NESTIN were upregulated while GAP43 had little change compared with the control groups.

\section{Discussion}

Compared with other mesenchymal stem cells (MSCs) derived from bone marrow, adipose tissue, peripheral blood, and umbilical cord blood, MSCs derived from dental tissues have marked advantages of easy access with least invasive procedures without any ethical issues [36]. The ability to undergo self-renewal and multidifferentiation is the most remarkable characteristic of DTSCs, which make them particularly suited for tissue engineering and gene therapy application. Before using DTSCs for clinical therapy, the ability of in vitro expansion and differentiation should be 

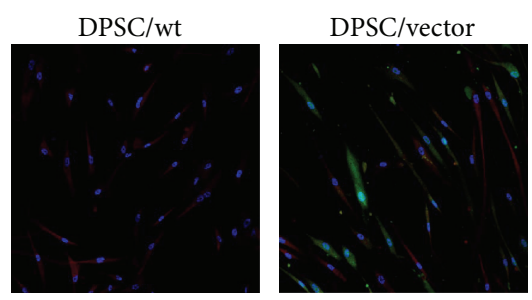

(a)
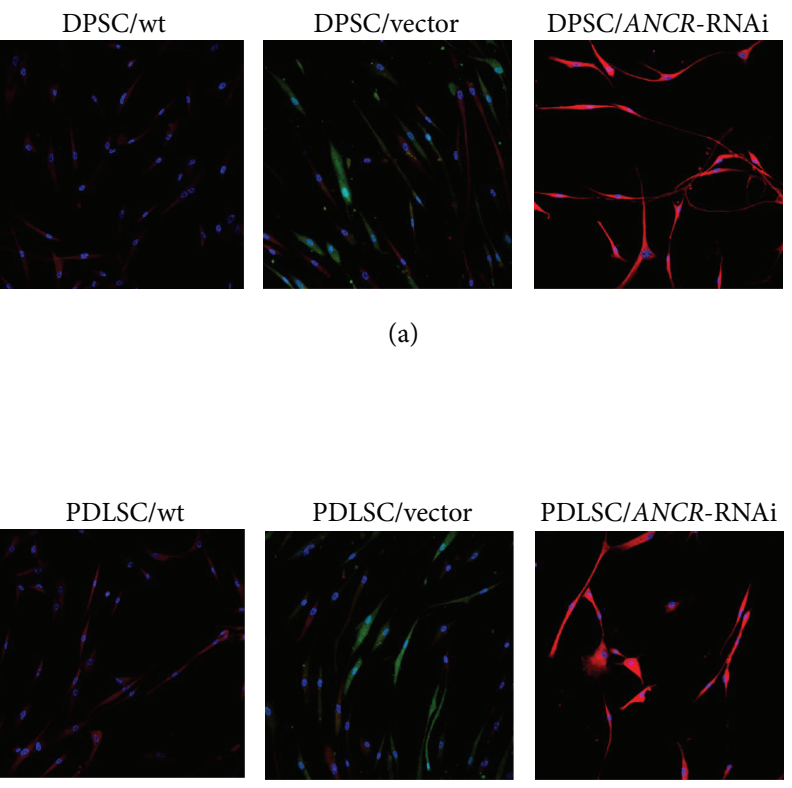

(b)

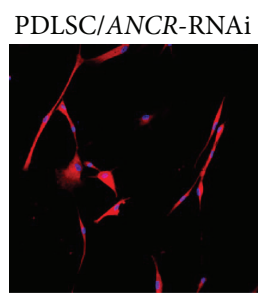

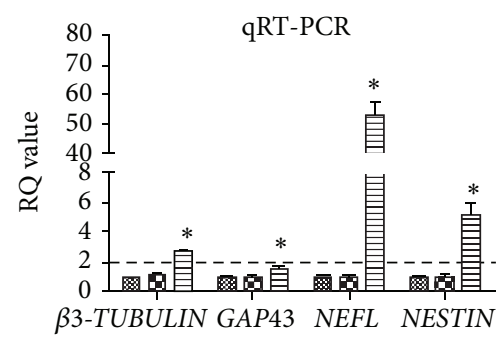

冈DPSC-wt $\boxminus$ DPSC-ANCRi

$\triangle$ DPSC-vector

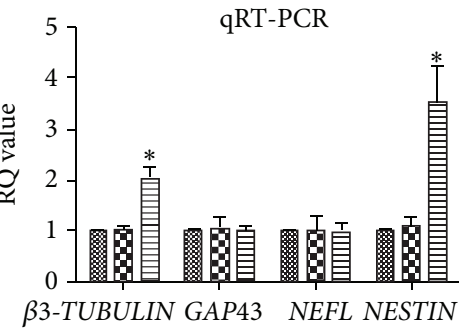

잠 PDLSC-wt PDLSC-vector

(e)
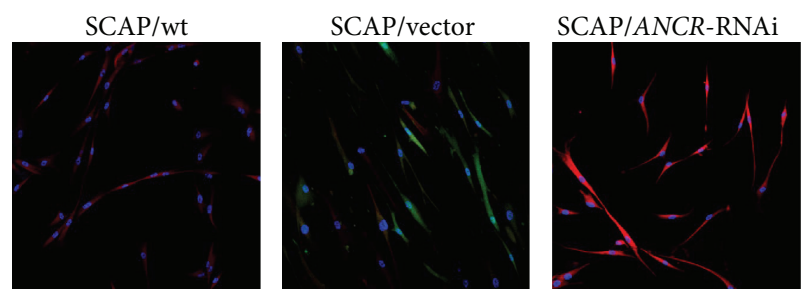

(c)

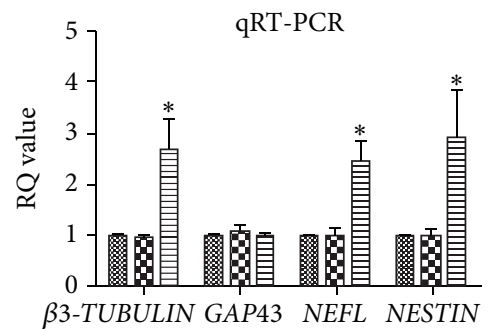

SCAP-wt $\quad$ SCAP-vector
SCAP-ANCRi

(f)

FIGURE 5: The effect of ANCR-RNAi on neurogenic differentiation in DTSCs. Immunofluorescence results showed that the expression of BIII-TUBULIN on DPSC/ANCR-RNAi (a), PDLSC/ANCR-RNAi (b), and SCAP/ANCR-RNAi (c) cells was stronger than control groups. The green is the color of GFP (Green Fluorescent Protein) transfected by the vector. The red is the color of $\beta I I I-T U B U L I N$ stained by DyLight 405. The morphology of DPSC/ANCR-RNAi and PDLSC/ANCR-RNAi cells was remarkably changed. The mRNA expressions of $\beta I I I-T U B U L I N$, GAP43, NEFL, and NESTIN were upregulated in DPSC/ANCR-RNAi cells (d) after 2 weeks of induction. In PDLSC/ANCR-RNAi cells (e), BIII-TUBULIN and NESTIN were upregulated, while GAP43 and NEFL had little change compared with control groups. In SCAP/ANCRRNAi cells (f), $\beta I I I-T U B U L I N, N E F L$, and NESTIN were upregulated while GAP43 had little change compared with control groups. ${ }^{*} P<0.05$ when compared with the control group.

taken into account. A range of factors participate in the regulation of DTSCs differentiation and proliferation [37]. We herein used a laterally comparative analysis to investigate the role of long noncoding RNA-ANCR in regulating the ex vivo expansion and differentiation of three types of DTSCs, including DPSCs, PDLSCs, and SCAP.

Under osteogenic conditions, the ANCR-RNAi cells highly mineralized compared with the control groups demonstrated by the quantification of the Alizarin red staining, as well as the ALP activity. These results indicate that downregulation of $A N C R$ may promote osteogenic differentiation of DTSCs. Thus to further confirm osteogenic differentiation thoroughly, we chose to evaluate the expression of several osteogenic related genes (including OCN, BSP, and $A L P$ ). $O C N$ is secreted solely by osteoblasts and often used as a marker for the bone formation process [38]. Its gene expression is recognized to increase at a late stage of osteoblastic differentiation [39]. BSP, a component of mineralized tissues such as bone, dentin, and calcified cartilage, is considered as a specific marker for osteoblasts [40]. The gene expression of $O C N, B S P$, and $A L P$ was upregulated in the ANCR-RNAi cells compared with control groups. Taken together, we speculate 
that the osteogenic differentiation of DTSCs that is promoted by downregulated $A N C R$ is implemented by upregulating $O C N, B S P$, and $A L P$.

Downregulation of $A N C R$ promoted the adipogenic differentiation of DTSCs demonstrated by Oil red $\mathrm{O}$ staining and confirmed by $P P A R-\gamma 2$ and $C / E B P \alpha$ expression. More lipid droplets were form in DTSCs/ANCR-RNAi cells compared with the control groups. And the gene expression of $P P A R-\gamma 2$ and $C / E B P \alpha$ was upregulated after the downregulation of $A N C R$. PPAR $\gamma-2$ is known as a transcription factor in the directed differentiation of preadipocytes that is specifically expressed at the early stage of adipocyte differentiation. It is a key factor in adipogenic differentiation. $C / E B P \alpha$ works with $P P A R \gamma-2$ to promote adipogenic differentiation [41]. We speculate that promotion of adipogenic differentiation caused by downregulating $A N C R$ is implemented by upregulating $P P A R \gamma-2$ and $C / E B P \alpha$.

BIII-TUBULIN is often identified as the structural protein of neuronal cells. It plays a vital role in the process of neurogenic differentiation [42]. After two weeks of neurogenic differentiation induction, we examined the immunofluorescence staining of $\beta I I I-T U B U L I N$. Compared with the control groups, the morphology of DPSC/ANCR-RNAi cells and PDLSC/ANCR-RNAi cells was obviously changed. The morphology of DPSC/ANCR-RNAi cells was similar to neuronallike cells. There were several axon-like structures extending from the cell body that connected with adjacent cells. The morphology of the PDLSC/ANCR-RNAi cells was changed from long fusiform cells into irregular triangles or ovals, with no axon-like structures, while the morphology of the control cells became long and thin. This same long, thin morphology was observed in SCAP/ANCR-RNAi cells and the control groups. There was little difference between the SCAP/ANCRRNAi cells and control groups. The red fluorescence of $\beta I I I-$ TUBULIN became more obvious after ANCR downregulation in DPSCs, PDLSCs, and SCAP.

We used Q-PCR to evaluate the gene expression of $\beta I I I-$ TUBULIN, GAP43, neurofilament-light polypeptide (NEFL), and NESTIN. The $\beta I I I-T U B U L I N$ expression was upregulated after downregulation of ANCR in DTSCs. These results could explain the increased red fluorescence of $\beta I I I-T U B U L I N$ in DTSC/ANCR-RNAi cells. NESTIN, an intermediate filament protein, is an important surface marker on neural progenitor cells [43]. Q-PCR showed that NESTIN expression was upregulated after downregulating ANCR in DTSCs. GAP43 or neuromodulin is a neural specific axon membrane protein, which plays a vital role in axonogenesis [44]. The expression of GAP43 was upregulated in DPSCs but was not significantly different in PDLSCs and SCAP. NEFL is a key protein in axon intermediate filament formation that also plays an important role in axonogenesis [21]. After $A N C R$ downregulation in DPSCs, the expression of NEFL was increased more than 50-fold compared with the control groups, indicating that DPSC/ANCR-RNAi cells have very strong axonogenesis. However, the expression of NEFL was approximately twofold higher in SCAP/ANCR-RNAi but largely unchanged in PDLSCs compared with the control groups. We found that the changes in the expression of GAP43 and NEFL were in accordance with the morphology changes of DTSCs/ANCR-RNAi cells. From these data, we concluded that downregulating $A N C R$ promoted neurogenic differentiation of DTSCs and that the neurogenic differentiation potential of DPSCs was more obviously enhanced by downregulated ANCR compared with PDLSCs and SCAP.

As for the proliferation aspect, the regulation effect of $A N C R$ on three types of DTSCs was different. Downregulation of $A N C R$ promoted the proliferation of PDLSCs but had little effect on DPSCs and SCAP proliferation. We used cck- 8 and Edu assay to confirm this results. Previous studies demonstrate that stem cells derived from dental tissues show a difference in terms of cell proliferation [3, 45]. Although most of stem cells from dental tissues exhibit the similar fibroblast-like morphology and clonogenic abilities after in vitro expansion, they orient from different niches of postnatal stem cells. The stem cells niches refer to an in vivo or in vitro stem cells microenvironment which maintain stem cells in a quiescent state $[46,47]$. However, following tissue injury, the surrounding microenvironment interacts with stem cells to regulate cell fate. Stem cells behaviours (self-renewal or differentiation for tissue regeneration) are mainly governed by these distinct microenvironment which includes growth factors, cytokines, and extracellular matrix components, as well as cell signaling pathways [48]. A recent study in rats demonstrates that Notch signaling pathway plays a vital role in controlling DTSCs fate during the tooth development [49]. Additionally, our previous research found that ANCR promotes the proliferation and osteogenic differentiation of PDLSCs by activating the canonical Wnt signaling pathway [34]. The canonical Wnt signaling pathway which is an ancient and evolutionarily conserved pathway extensively participates in osteogenic, adipogenic, and neurogenic differentiation of stem cells [50]. It has been demonstrated that downregulating $A N C R$ promotes osteoblast differentiation by targeting EZH2 and regulating Runx2 expression [33]. EZH2 is known to be a key cellular homeostasis and differentiation regulator which interacts with canonical Wnt signaling pathway in stem cells [51]. Based on these researches, we speculate that ANCR may interact with EZH2 via canonical Wnt signaling pathway, thus regulating the DTSCs differentiation. Belonging to lncRNA, ANCR acts as the upstream of the regulatory network. It is a novel factor in regulating stem cells behaviours. Therefore, further in-depth investigation shall be performed to fully evaluate the control mechanism of lncRNA-ANCR during the proliferation and differentiation of DTSCs, as well as crosstalk between multiple pathways regulated by $A N C R$.

\section{Conclusion}

This study demonstrates that lncRNA-ANCR acts as a key regulator in terms of DTSCs proliferation and multiple-potential of differentiation. Downregulation of ANCR promoted the proliferation of PDLSCs, as well as osteogenic, adipogenic, and neurogenic differentiation of DTSCs (DPSCs, PDLSCs, and SCAP). More work is required to investigate the related genes and signaling pathways via regulation of ANCR controlling the DTSCs behaviours. This study represents a step 
forward in providing a novel regulator factor for further research in better understanding the behaviours of stem cells from dental tissues.

\section{Competing Interests}

The authors deny any competing interests.

\section{Authors' Contributions}

Qian Jia, Xiaolin Chen, and Wenkai Jiang contributed equally to this work.

\section{Acknowledgments}

This study was supported by grants from the National Natural Science Foundation of China (no. 81371139 and no. 81470754) and the National Key Technologies R\&D Program of the Twelve-Five Year Plan, the Ministry of Science and Technology of China (2012BAI07B03).

\section{References}

[1] S. Gronthos, M. Mankani, J. Brahim, P. G. Robey, and S. Shi, "Postnatal human dental pulp stem cells (DPSCs) in vitro and in vivo," Proceedings of the National Academy of Sciences of the United States of America, vol. 97, no. 25, pp. 13625-13630, 2000.

[2] B.-M. Seo, M. Miura, S. Gronthos et al., "Investigation of multipotent postnatal stem cells from human periodontal ligament," The Lancet, vol. 364, no. 9429, pp. 149-155, 2004.

[3] W. Sonoyama, Y. Liu, T. Yamaza et al., "Characterization of the apical papilla and its residing stem cells from human immature permanent teeth: a pilot study," Journal of Endodontics, vol. 34, no. 2, pp. 166-171, 2008.

[4] B. Song, W. Jiang, A. Alraies et al., "Bladder smooth muscle cells differentiation from dental pulp stem cells: future potential for bladder tissue engineering," Stem Cells International, vol. 2016, Article ID 6979368, 11 pages, 2016.

[5] P. Hilkens, P. Gervois, Y. Fanton et al., "Effect of isolation methodology on stem cell properties and multilineage differentiation potential of human dental pulp stem cells," Cell and Tissue Research, vol. 353, no. 1, pp. 65-78, 2013.

[6] B.-C. Kim, H. Bae, I.-K. Kwon et al., "Osteoblastic/cementoblastic and neural differentiation of dental stem cells and their applications to tissue engineering and regenerative medicine," Tissue Engineering Part B: Reviews, vol. 18, no. 3, pp. 235-244, 2012.

[7] W. L. Dissanayaka, X. Zhan, C. Zhang, K. M. Hargreaves, L. Jin, and E. H. Y. Tong, "Coculture of dental pulp stem cells with endothelial cells enhances osteo-/odontogenic and angiogenic potential in vitro," Journal of Endodontics, vol. 38, no. 4, pp. 454463, 2012.

[8] K. Janebodin, Y. Zeng, W. Buranaphatthana, N. Ieronimakis, and M. Reyes, "VEGFR2-dependent angiogenic capacity of pericyte-like dental pulp stem cells," Journal of Dental Research, vol. 92, no. 6, pp. 524-531, 2013.

[9] W. Sonoyama, Y. Liu, D. Fang et al., "Mesenchymal stem cellmediated functional tooth regeneration in swine," PLoS ONE, vol. 1, no. 1, article e79, 2006.
[10] T. Osathanon, N. Nowwarote, and P. Pavasant, "Basic fibroblast growth factor inhibits mineralization but induces neuronal differentiation by human dental pulp stem cells through a FGFR and PLC $\gamma$ signaling pathway," Journal of Cellular Biochemistry, vol. 112, no. 7, pp. 1807-1816, 2011.

[11] X. Feng, D. Huang, X. Lu et al., "Insulin-like growth factor 1 can promote proliferation and osteogenic differentiation of human dental pulp stem cells via mTOR pathway," Development Growth and Differentiation, vol. 56, no. 9, pp. 615-624, 2014.

[12] W. He, Z. Wang, Z. Luo et al., "LPS promote the odontoblastic differentiation of human dental pulp stem cells via MAPK signaling pathway," Journal of Cellular Physiology, vol. 230, no. 3, pp. 554-561, 2015.

[13] X. Yang, S. Zhang, X. Pang, and M. Fan, "Pro-inflammatory cytokines induce odontogenic differentiation of dental pulpderived stem cells," Journal of Cellular Biochemistry, vol. 113, no. 2, pp. 669-677, 2012.

[14] I. Gay, A. Cavender, D. Peto et al., "Differentiation of human dental stem cells reveals a role for microRNA-218," Journal of Periodontal Research, vol. 49, no. 1, pp. 110-120, 2014.

[15] E. S. Hara, M. Ono, T. Eguchi et al., "MiRNA-720 controls stem cell phenotype, proliferation and differentiation of human dental pulp cells," PLoS ONE, vol. 8, no. 12, article e83545, 2013.

[16] F. Wei, D. Liu, C. Feng et al., "MicroRNA-21 mediates stretchinduced osteogenic differentiation in human periodontal ligament stem cells," Stem Cells and Development, vol. 24, no. 3, pp. 312-319, 2015.

[17] G. Ye, C. Li, X. Xiang et al., "Bone morphogenetic protein-9 induces PDLSCs osteogenic differentiation through the ERK and p38 signal pathways," International Journal of Medical Sciences, vol. 11, no. 10, pp. 1065-1072, 2014.

[18] T. Osathanon, N. Nowwarote, J. Manokawinchoke, and P. Pavasant, "BFGF and JAGGED1 regulate alkaline phosphatase expression and mineralization in dental tissue-derived mesenchymal stem cells," Journal of Cellular Biochemistry, vol. 114, no. 11, pp. 2551-2561, 2013.

[19] X. Chen, C. Hu, G. Wang et al., "Nuclear factor- $\kappa$ B modulates osteogenesis of periodontal ligament stem cells through competition with $\beta$-catenin signaling in inflammatory microenvironments," Cell Death \& Disease, vol. 4, no. 2, article e510, 2013.

[20] D.-S. Song, J.-C. Park, I.-H. Jung et al., "Enhanced adipogenic differentiation and reduced collagen synthesis induced by human periodontal ligament stem cells might underlie the negative effect of recombinant human bone morphogenetic protein-2 on periodontal regeneration," Journal of Periodontal Research, vol. 46, no. 2, pp. 193-203, 2011.

[21] T. Osathanon, J. Manokawinchoke, N. Nowwarote, P. Aguilar, T. Palaga, and P. Pavasant, "Notch signaling is involved in neurogenic commitment of human periodontal ligament-derived mesenchymal stem cells," Stem Cells and Development, vol. 22, no. 8, pp. 1220-1231, 2013.

[22] J. Wu, G. T.-J. Huang, W. He et al., "Basic fibroblast growth factor enhances stemness of human stem cells from the apical papilla," Journal of Endodontics, vol. 38, no. 5, pp. 614-622, 2012.

[23] J. Wang, B. Liu, S. Gu, and J. Liang, "Effects of Wnt/ $\beta$-catenin signalling on proliferation and differentiation of apical papilla stem cells," Cell Proliferation, vol. 45, no. 2, pp. 121-131, 2012.

[24] W. Zhang, X. Zhang, J. Ling et al., "Proliferation and odontogenic differentiation of BMP2 gene-transfected stem cells from human tooth apical papilla: An In Vitro Study," International Journal of Molecular Medicine, vol. 34, no. 4, pp. 1004-1012, 2014. 
[25] Y. Li, M. Yan, Z. Wang et al., "17 $\beta$-estradiol promotes the odonto/osteogenic differentiation of stem cells from apical papilla via mitogen-activated protein kinase pathway," Stem Cell Research \& Therapy, vol. 5, no. 6, p. 125, 2014.

[26] L. Lipovich, R. Johnson, and C.-Y. Lin, "MacroRNA underdogs in a microRNA world: evolutionary, regulatory, and biomedical significance of mammalian long non-protein-coding RNA," Biochimica et Biophysica Acta (BBA)—Gene Regulatory Mechanisms, vol. 1799, no. 9, pp. 597-615, 2010.

[27] J. Ponjavic, C. P. Ponting, and G. Lunter, "Functionality or transcriptional noise? Evidence for selection within long noncoding RNAs," Genome Research, vol. 17, no. 5, pp. 556-565, 2007.

[28] H. van Bakel, C. Nislow, B. J. Blencowe, and T. R. Hughes, "Most 'dark matter' transcripts are associated with known genes," PLoS Biology, vol. 8, no. 5, article e1000371, 2010.

[29] M. E. Dinger, D. K. Gascoigne, and J. S. Mattick, "The evolution of RNAs with multiple functions," Biochimie, vol. 93, no. 11, pp. 2013-2018, 2011.

[30] C. P. Ponting, P. L. Oliver, and W. Reik, "Evolution and functions of long noncoding RNAs," Cell, vol. 136, no. 4, pp. 629-641, 2009.

[31] M. Guttman, I. Amit, M. Garber et al., "Chromatin signature reveals over a thousand highly conserved large non-coding RNAs in mammals," Nature, vol. 458, no. 7235, pp. 223-227, 2009.

[32] M. Kretz, D. E. Webster, R. J. Flockhart et al., "Suppression of progenitor differentiation requires the long noncoding RNA ANCR," Genes and Development, vol. 26, no. 4, pp. 338-343, 2012.

[33] L. Zhu and P.-C. Xu, "Downregulated LncRNA-ANCR promotes osteoblast differentiation by targeting EZH2 and regulating Runx2 expression," Biochemical and Biophysical Research Communications, vol. 432, no. 4, pp. 612-617, 2013.

[34] Q. Jia, W. Jiang, and L. Ni, "Down-regulated non-coding RNA (lncRNA-ANCR) promotes osteogenic differentiation of periodontal ligament stem cells," Archives of Oral Biology, vol. 60, no. 2, pp. 234-241, 2015.

[35] W. Jiang, H. Lv, H. Wang et al., "Activation of the NLRP3/ caspase-1 inflammasome in human dental pulp tissue and human dental pulp fibroblasts," Cell and Tissue Research, vol. 361, no. 2, pp. 541-555, 2015.

[36] W. Jiang, L. Ni, A. Sloan, and B. Song, "Tissue engineering and regenerative medicine, from and beyond the dentistry," Dentistry, vol. 5, no. 6, article 306, 2015.

[37] P. D. Potdar and Y. D. Jethmalani, "Human dental pulp stem cells: applications in future regenerative medicine," World Journal of Stem Cells, vol. 7, no. 5, pp. 839-851, 2015.

[38] N. K. Lee, H. Sowa, E. Hinoi et al., "Endocrine regulation of energy metabolism by the skeleton," Cell, vol. 130, no. 3, pp. 456469, 2007.

[39] M. Mizuno and Y. Kuboki, "Osteoblast-related gene expression of bone marrow cells during the osteoblastic differentiation induced by type I collagen," Journal of Biochemistry, vol. 129, no. 1, pp. 133-138, 2001.

[40] Y. Ogata, "Bone sialoprotein and its transcriptional regulatory mechanism," Journal of Periodontal Research, vol. 43, no. 2, pp. 127-135, 2008.

[41] R. Siersbæk, R. Nielsen, and S. Mandrup, "PPAR $\gamma$ in adipocyte differentiation and metabolism-novel insights from genomewide studies," FEBS Letters, vol. 584, no. 15, pp. 3242-3249, 2010.

[42] B. Mead, A. Logan, M. Berry, W. Leadbeater, and B. A. Scheven, "Intravitreally transplanted dental pulp stem cells promote neuroprotection and axon regeneration of retinal ganglion cells after optic nerve injury," Investigative Ophthalmology and Visual Science, vol. 54, no. 12, pp. 7544-7556, 2013.

[43] J.-S. Ryu, K. Ko, J.-W. Lee et al., "Gangliosides are involved in neural differentiation of human dental pulp-derived stem cells," Biochemical and Biophysical Research Communications, vol. 387, no. 2, pp. 266-271, 2009.

[44] R. B. Bressan, F. R. Melo, P. A. Almeida et al., "EGF-FGF2 stimulates the proliferation and improves the neuronal commitment of mouse epidermal neural crest stem cells (EPI-NCSCs)," Experimental Cell Research, vol. 327, no. 1, pp. 37-47, 2014.

[45] E. Eleuterio, O. Trubiani, M. Sulpizio et al., "Proteome of human stem cells from periodontal ligament and dental pulp," PLoS ONE, vol. 8, no. 8, Article ID e71101, 2013.

[46] P. Bianco and P. G. Robey, "Stem cells in tissue engineering," Nature, vol. 414, no. 6859, pp. 118-121, 2001.

[47] E. Fuchs and J. A. Segre, "Stem cells: a new lease on life," Cell, vol. 100, no. 1, pp. 143-155, 2000.

[48] K. A. Moore and I. R. Lemischka, "Stem cells and their niches," Science, vol. 311, no. 5769, pp. 1880-1885, 2006.

[49] H. Løvschall, M. Tummers, I. Thesleff, E.-M. Füchtbauer, and K. Poulsen, "Activation of the Notch signaling pathway in response to pulp capping of rat molars," European Journal of Oral Sciences, vol. 113, no. 4, pp. 312-317, 2005.

[50] C. Y. Logan and R. Nusse, "The Wnt signaling pathway in development and disease," Annual Review of Cell and Developmental Biology, vol. 20, pp. 781-810, 2004.

[51] Y.-H. Chen, M.-C. Hung, and L.-Y. Li, "EZH2: a pivotal regulator in controlling cell differentiation," American Journal of Translational Research, vol. 4, no. 4, pp. 364-375, 2012. 

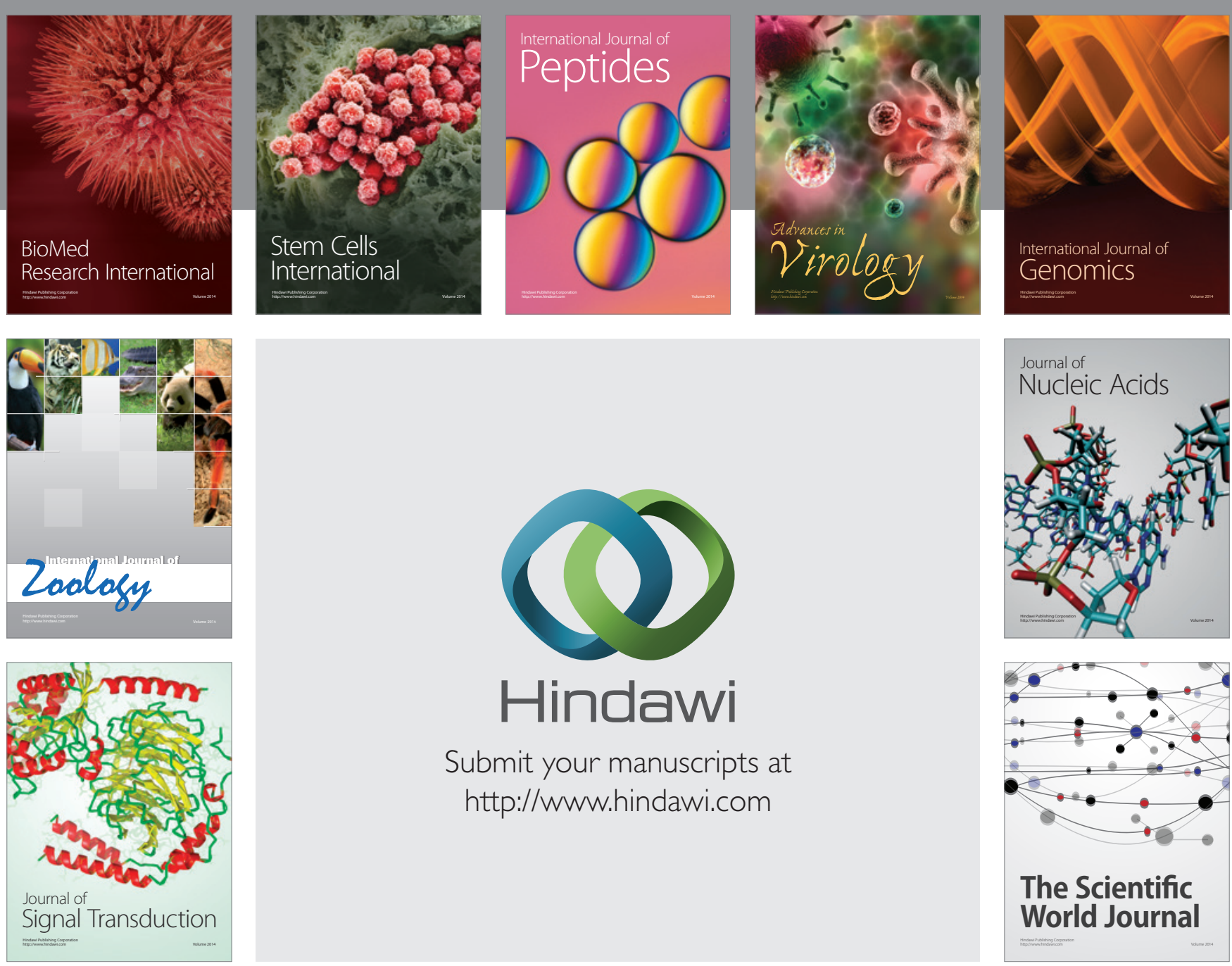

Submit your manuscripts at

http://www.hindawi.com
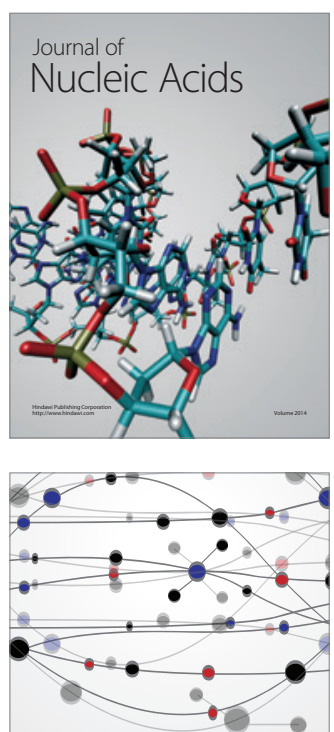

The Scientific World Journal
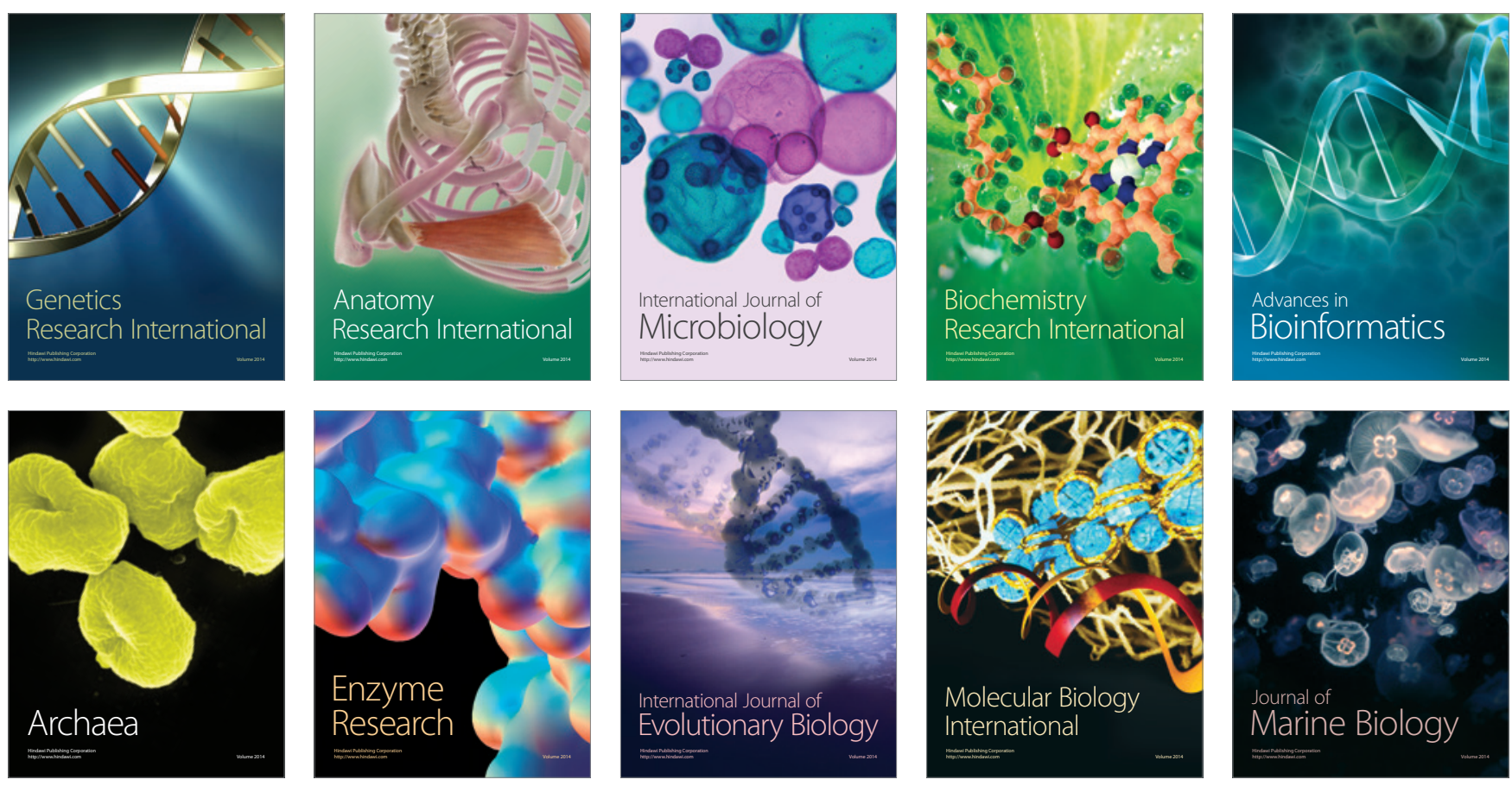